Marliza VIeira Cunha RUdGe' Iracema de Mattos Paranhos Calderon ${ }^{2}$

Técia Maria de Oliverira Maranhão ${ }^{3}$ George Dantas de Azevedo ${ }^{4}$

Editorial

\section{Perfil da pós-graduação em Ginecologia e Obstetrícia no Brasil}

\author{
Profile of the Brazilian postgraduate study programs in Gynecology \\ and Obstetrics
}

Ainda em desenvolvimento e tomando contornos mais sólidos, os programas de pósgraduação (PG) stricto sensu em Ginecologia e Obstetrícia (GO) vêm, progressivamente, se aperfeiçoando na formação de recursos humanos na área da Saúde da Mulher. Responsáveis por incrementar o currículo dos médicos com mestrados e doutorados, os cursos inserem, no mercado, profissionais aptos para desenvolver atividades de pesquisa.

Nesse contexto de formação, torna-se importante entender que a PG não visa exclusivamente ao aperfeiçoamento em GO, e sim à formação do professor e do pesquisador. Assim, as disciplinas ministradas nos diversos programas devem ter como foco principal a formação do pesquisador e não do médico especialista em GO. Reforçando esta orientação, a maioria dos programas de PG em GO não é voltada apenas para os tocoginecologistas, havendo abertura para todos os profissionais da Saúde interessados em fazer pesquisa na área. Cada vez mais, a geração do conhecimento assume caráter multidisciplinar ${ }^{1}$ e exige atividades compatíveis com a formação de um pesquisador, independentemente da especialidade.

\section{O sistema de avaliação dos programas de PG}

A avaliação dos programas de PG no Brasil é realizada de forma continuada pela Coordenação de Aperfeiçoamento de Pessoal de Nível Superior (CAPES), fundação do Ministério da Educação (MEC). Inicia-se pela análise de um relatório anual e é consolidada a cada triênio, resultando num sistema de classificação por conceitos atribuídos aos programas de PG.

De acordo com a própria CAPES, a ficha de avaliação é o instrumento em que são especificados os aspectos a serem analisados e valorizados no processo e o aplicativo utilizado para o registro dos resultados da avaliação de cada programa. Sua concepção assegura a indispensável base de uniformidade e padronização do processo desenvolvido pelas diferentes áreas, sem, contudo, deixar de atender às especificidades de cada área²

$\mathrm{Na}$ avaliação do último triênio (2004-2006), os cinco quesitos para a avaliação foram assim definidos: Proposta do Programa, Corpo Docente, Corpo Discente, Teses e Dissertações, Produção Intelectual e Inserção Social. Um sexto quesito, correspondente aos critérios para a atribuição dos conceitos 6 e 7, foi aplicado exclusivamente aos programas que obtiveram conceito 5 na avaliação das comissões de área e foram considerados elegíveis para a atribuição

Programa de Pós-Graduação em Ginecologia, Obstetrícia e Mastologia da Faculdade de Medicina de Botucatu da Universidade Estadual Paulista "Júlio de Mesquita Filho" - UNESP - Botucatu (SP), Brasil; Pós-graduação em Ciências da Saúde da Universidade Federal do Rio Grande do Norte - UFRN - Natal (RN), Brasil.

Professora Titular do Departamento de Ginecologia e Obstetrícia e Orientadora do Programa de Pós-graduação em Ginecologia, Obstetrícia e Mastologia da Universidade Estadual Paulista "Júlio de Mesquita Filho" - UNESP - Botucatu (SP), Brasil.

2 Livre Docente Professora do Departamento de Ginecologia e Obstetrícia e Coordenadora do Programa de Pós-graduação em Ginecologia, Obstetrícia e Mastologia da Universidade Estadual Paulista "Júlio de Mesquita Filho" - UNESP - Botucatu (SP), Brasil.

3 Professora Titular do Departamento de Tocoginecologia e Coordenadora do Programa de Pós-graduação em Ciências da Saúde da Universidade Federal do Rio Grande do Norte - UFRN - Natal (RN), Brasil.

4 Professor Adjunto do Departamento de Morfologia e Orientador do Programa de Pós-graduação em Ciências da Saúde da Universidade Federal do Rio Grande do Norte - UFRN - Natal (RN), Brasil 
desses conceitos de excelência. Entretanto, coube ao Comitê Técnico-Científico (CTC) da CAPES a avaliação e atribuição dos conceitos finais aos programas de PG.

Os aspectos básicos são focalizados nos quesitos de avaliação, que são: a proposta do programa, corpo docente, corpo discente, produção intelectual, inserção social e os diferenciais de alta qualificação e desempenho e de forte liderança nacional.

Na avaliação trienal, os programas com conceito 6 e 7 são considerados os de excelência; os com conceito 5 são considerados muito bons; os com conceito 4 são bons; e os com conceito 3 são regulares. De acordo com esse sistema de classificação, os programas avaliados com conceitos de 3 a 7 são recomendados pela CAPES e, na prática, estão autorizados a funcionar e a receber novos alunos; os que recebem conceitos 1 ou 2 não são reconhecidos pela CAPES, são descredenciados e não podem receber novos alunos ${ }^{3}$.

\section{A situação atual dos programas de PG em GO}

No último triênio (2004-2006), a avaliação da CAPES atribuiu conceitos que variaram de 3 a 5 a 11 programas de PG na área de GO. Portanto, todos os programas receberam aval para continuar atuando e recebendo novos alunos, a partir de 2007. Estes programas estão assim distribuídos: um no Maranhão, Pernambuco, Rio Grande do Norte e Minas Gerais e sete em São Paulo. De acordo com os conceitos atribuídos, dois programas são regulares (conceito 3), quatro são bons (conceito 4) e cinco deles são muito bons (conceito 5). Não temos, até o momento, nenhum programa de excelência (conceitos 6 e 7) na área de GO. Com exceção do programa de PG em Saúde Materno-Infantil, com nível apenas de mestrado, da Universidade Federal do Maranhão (UFMA), que se iniciou em 2005 e ainda não completou um triênio, todos os demais programas já foram avaliados por dois ou três triênios. Isto significa que a progressão dos conceitos para a qualificação dos programas de PG, na área de GO, está ainda muito morosa. Além disso, neste último triênio, dentre os dez programas que tiveram pelo menos uma avaliação trienal prévia, apenas dois evoluíram no conceito, passando de 4 para 5 , sete deles permaneceram com o mesmo conceito do triênio anterior e um programa caiu de conceito 5 para $4^{3}$.

Vários fatores contribuem para esse quadro. De acordo com especialista da área, ainda persistem alguns pontos negativos que pesam muito na avaliação da CAPES, dentre eles: "a não diferenciação da maioria dos programas, entre lato e stricto sensu"; "a falta de esclarecimento do profissional, especialista em GO, sobre o que é PG e o que é especialização"; "a falta de apoio e envolvimento das instituições de ensino e das sociedades de classe na valorização das pesquisas e dos programas de PG"; "a carência de revistas nacionais indexadas da especialidade, contribuindo para a baixa internacionalização das pesquisas realizadas no Brasil”.

Entretanto, alguns pontos positivos podem ser identificados. Esses pontos vêm do atual momento que está vivendo a PG, em resposta à avaliação da CAPES, já que os programas começam a se interessar pela qualidade do recurso humano formado, das pesquisas e, conseqüentemente, das publicações, mas isso é apenas o início. Esse movimento precisa ser intensificado e envolver não só a academia, mas também as sociedades de classe e escolas médicas como um todo ${ }^{1}$.

\section{Perspectivas de fortalecimento da PG em GO no Brasil}

O que pesa na avaliação da CAPES? Cada uma das 45 áreas do conhecimento em que atua a CAPES tem seus critérios de avaliação, mas há uma filosofia comum a todas. Na opinião de Ribeiro ${ }^{4}$, Diretor de Avaliação da CAPES, o entendimento do que a instituição considera produção científica, distribuição desta produção, formação de alunos e distribuição na orientação desses alunos gera muita confusão, mas é assunto fundamental.

Nesse contexto, vale a pena transcrever alguns trechos do artigo de Ribeiro ${ }^{4}$ na página da CAPES: "Podemos dizer que o primeiro critério na CAPES é que, para alguém orientar ou mesmo lecionar na PG, é decisivo que seja pesquisador. Na graduação, entende-se e é necessário que um professor seja um bom didata, mesmo que não se dedique à pesquisa inovadora (mas precisa atualizar-se com os resultados da pesquisa de ponta). Na PG, o volume de aulas é menor e, por isso mesmo, a questão da boa didática é menos importante do que a da qualidade da pesquisa que o docente faz e na qual leva seu aluno a mergulhar. Em outras palavras, só ensina a pesquisar quem pesquisa. Isto requer um primeiro ponto, que é como se mede a pesquisa. Uma das maiores ilusões sobre a CAPES é a do assim-chamado "produtivismo", isto é, a idéia de que a agência só quer saber se e quanto você produz. Não é verdade. O mais importante é a qualidade do que se produz. Evidentemente, só podemos saber da produção científica quando ela é publicada. É quando ela se torna fecunda, quando se expõe a críticas, que podem ser devastadoras, mas quase sempre têm um efeito construtivo, e quando pode influenciar leitores e levá-los a citá-la em suas próprias pesquisas. Publicar é então o meio de difundir a produção, de socializá-la”. 
Continuando, as reflexões de Ribeiro ${ }^{4}$ destacam: "Mas adiantaria muito se, num programa, um, dois ou três docentes respondessem pela produção científica, enquanto os outros dessem aulas e orientassem? O que se deseja é um equilíbrio na produção intelectual, respeitada evidentemente a diferença entre seniores e juniores, entre docentes mais maduros e mais novos, que leve um aluno a sentir segurança de que será orientado por um pesquisador de verdade, e não por alguém sem experiência de pesquisa. Isso é o que se chama distribuição da produção científica. As áreas fixam faixas distintas, mas digamos que é razoável supor que dois terços do corpo docente de um curso, pelo menos, atendam a um ritmo de publicação de determinada qualidade, para a CAPES poder dar uma nota que indica, com pequena margem de erro, que o aluno será orientado no patamar daquele curso (que pode ter nota regular, boa, muito boa ou excelente). Ou seja, um curso muito bom não é aquele que tem dois ou três professores excelentes e vinte apenas regulares. É um curso que tem sua linha de equilíbrio no muito bom, e, portanto assegura aos seus alunos uma chance elevada de ter professores e orientadores desse quilate".

Sobre a formação de mestres e doutores, Ribeiro ${ }^{4}$ pondera que: "Mas, se parássemos aí, estaríamos fazendo a avaliação dos grupos de pesquisa. O CNPq, nossa agência irmã, tem um importante diretório de grupos de pesquisa. Mas há algo que falta ao conceito de grupo de pesquisa: ele não forma pessoas. Como o Brasil faz sua avaliação dos cursos de mestrado e doutorado a partir da CAPES, que tem no nome o aperfeiçoamento do pessoal de nível superior, nosso principal "produto" não são os artigos e livros, nem mesmo as teses e dissertações, mas os mestres e doutores que vão utilizar o conhecimento e a experiência adquirida para atuar quarenta, talvez cinqüenta anos na pesquisa ou na sua profissão. Por isso, é fundamental ver como se dá esta formação. Algumas áreas exigem que a tese ou dissertação resulte em publicações de um determinado nível de qualidade”. Este é um requisito de peso significativo nas nossas áreas de avaliação da CAPES. As áreas de Medicina II e III valorizam muito a proporção de discentes co-autores nas publicações, de preferência, em revistas internacionais indexadas.

Ainda segundo Ribeiro ${ }^{4}$ : "Da mesma forma que não é bom ter a produção intelectual de qualidade concentrada em poucos membros do programa, também é negativo ter a orientação conduzida apenas por pequena parte deles. Adaptemos o exemplo acima: imaginemos então que dois ou três professores concentrem a maior parte das orientações de um curso, enquanto vinte têm um desempenho pequeno. Ora, o que queremos é que o professor que pesquisa seja o mesmo que orienta. Se houver uma especialização de uns na orientação, outros na docência e outros, ainda, na pesquisa, o resultado será que os orientados não terão tido experiência real de pesquisa. É o contrário do que queremos”.

Com base nesses argumentos, acreditamos que vários fatores poderão contribuir para a expansão da PG na nossa área e maior qualificação dos programas já existentes, destacando-se: a celebração de convênios de cooperação entre os programas já credenciados, de forma a fortalecer as linhas de pesquisas atuais, criação de novas abordagens e desenvolvimento de projetos multicêntricos e de elevado impacto científico; apoio da FEBRASGO (Federação Brasileira das Associações de Ginecologia e Obstetrícia), pela implementação de medidas visando dar maior visibilidade às pesquisas realizadas no Brasil e auxiliar os programas de PG em GO, na busca pela maior qualificação, entre elas: "a inserção da temática na agenda dos congressos regionais e nacionais, valorização das experiências de orientadores e coordenadores de programas de PG nos eventos promovidos pelas federadas e identificação de grupos de pesquisa nas regiões Norte, Nordeste e Centro-Oeste, com necessidade de formação de novos programas”; “a Federação poderia atuar como facilitadora de cooperação entre os programas existentes no Brasil, bem como articulando o estabelecimento de acordos de cooperação e convênios entre os programas de PG do Brasil e do exterior, por meio de sua representação junto à International Federation of Gynecology and Obstetrics (FIGO) e outros organismos internacionais"; "além disso, torna-se necessário empreender esforços para a indexação da Revista Brasileira de Ginecologia e Obstetrícia (RBGO) em bases de dados internacionais, aumentando sua acessibilidade e conseqüente impacto científico".

\section{Considerações finais}

Em síntese, produção científica, distribuição desta produção, formação de alunos e distribuição na orientação desses alunos são pontos fundamentais para a qualificação dos programas de PG. Todos esses atributos são imprescindíveis para se atingir o conceito 5 (muito bom) e são pré-requisitos naturais para a busca da excelência dos programas de PG. Em outras palavras, tendo esses pré-requisitos, fatalmente, o programa muito bom alcançará os critérios para atingir a excelência (conceitos 6 e 7). Esta deve ser a meta dos programas de PG em GO no Brasil.

Finalmente, sabedores da realidade das pesquisas no Brasil, a associação dos programas por meio de acordos de cooperação, com desenvolvimento de projetos conjuntos, certamente facilitará a ascensão nos critérios de qualidade dos programas envolvidos. 


\section{Referências}

1. Rudge MVC. Cursos de pós-graduação em GO devem formar médicos-pesquisadores. J FEBRASGO. 2007;14(89):5.

2. Brasil. Ministério da Educação. Coordenação de Aperfeiçoamento de Pessoal de Nível Superior (CAPES). Critérios de avaliação: avaliação trienal 2007 (triênio 2004-2006): Grande Área Ciências da Saúde (Medicina I, Medicina II, Medicina III, Odontologia, Farmácia, Enfermagem, Educação Física, Saúde Coletiva) [Internet]. CAPES; 2007 [citado 2008 jul 22]. Disponível em: http://www.capes.gov.br/opencms/export/ sites/capes/download/avaliacao/CA2007_CienciasSaude.pdf

3. Brasil. Ministério da Educação. Coordenação de Aperfeiçoamento de Pessoal de Nível Superior (CAPES). Avaliação trienal $2004-2006$. Relatório da avaliação trienal de 2007: resultados finais [Internet]. CAPES; 2007 [citado 2008 Jul 22]. Disponível em: http://www.capes. gov.br/opencms/export/sites/capes/download/avaliacaotrienal/RelatorioAvTrienal_200721dez07.pdf

4. Ribeiro RJ. Os critérios da avaliação [Internet]. CAPES; 2007 [citado 2008 Jul 22]. Disponível em: http://www.capes.gov.br/opencms/ export/sites/capes/download/artigos/Artigo_10_08_07.pdf 